\title{
Simple Electrochemical Method for Deposition and Voltammetric Inspection of Silver Particles at the Liquid-Liquid Interface of a Thin-Film Electrode
}

\author{
Valentin Mirčeski*,† and Rubin Gulaboski ${ }^{\ddagger}$ \\ Institute of Chemistry, Faculty of Natural Sciences and Mathematics, Sts. Cyril and Methodius University, \\ P.O. Box 162, 1000 Skopje, Republic of Macedonia, and REQUIMTE Departamento de Quimica, \\ Faculdade de Ciencias, Universidade do Porto, Rua do Campo Alegre 687, Porto, Portugal
}

Received: November 16, 2005; In Final Form: December 21, 2005

\begin{abstract}
A novel experimental methodology for depositing and voltammetric study of Ag nanoparticles at the waternitrobenzene (W-NB) interface is proposed by means of thin-film electrodes. The electrode assembly consists of a graphite electrode modified with a thin NB film containing decamethylferrocene (DMFC) as a redox probe. In contact with an aqueous electrolyte containing $\mathrm{Ag}^{+}$ions, a heterogeneous electron-transfer reaction between $\mathrm{DMFC}_{(\mathrm{NB})}$ and $\mathrm{Ag}_{(\mathrm{W})}^{+}$takes place to form $\mathrm{DMFC}_{(\mathrm{NB})}^{+}$and $\mathrm{Ag}$ deposit at the $\mathrm{W}-\mathrm{NB}$ interface. Based on this interfacial reaction, two different deposition strategies have been applied. In the uncontrolled potential deposition protocol, the electrode is immersed into an $\mathrm{AgNO}_{3}$ aqueous solution for a certain period under open circuit conditions. Following the deposition step, the Ag-modified thin-film electrode is transferred into an aqueous electrolyte free of $\mathrm{Ag}^{+}$ions and voltammetrically inspected. In the second protocol the deposition was carried out under controlled potential conditions, i.e., in an aqueous electrolyte solution containing $\mathrm{Ag}^{+}$ions by permanent cycling of the electrode potential. In this procedure, $\mathrm{DMFC}_{(\mathrm{NB})}$ is electrochemically regenerated at the electrode surface, hence enabling continuation and voltammetric control of the $\mathrm{Ag}$ deposition. Hence, the overall electrochemical process can be regarded as an electrochemical reduction of $\mathrm{Ag}_{(\mathrm{W})}^{+}$at the $\mathrm{W}-\mathrm{NB}$ interface, where the redox couple DMFC ${ }^{+} / \mathrm{DMFC}$ acts as a mediator for shuttling electrons from the electrode to the $\mathrm{W}-\mathrm{NB}$ interface. Ag-particles deposited at the $\mathrm{W}-\mathrm{NB}$ interface affect the ion transfer across the interface, which provides the basis for voltammetric inspection of the metal deposit at the liquid-liquid interface with thin-film electrodes. Voltammetric properties of thin-film electrodes are particularly sensitive to the deposition procedure, reflecting differences in the properties of the Ag deposit. Moreover, this methodology is particularly suited to inspect catalytic activities of metal particles deposited at the liquid-liquid interface toward heterogeneous electron-transfer reactions occurring at the at the liquidliquid interface.
\end{abstract}

\section{Introduction}

The interest for metal nanoparticles deposited at the interface between two immiscible liquids has increased in the past decades due to potential applications of these systems in various areas such as electronics, catalysis, and biology. A variety of chemical methods have been reported for synthesizing metal nanonanoparticles in a single phase $^{1}$ or at the liquid-liquid $(\mathrm{L}-\mathrm{L})$ interface, ${ }^{2-8}$ as well as for controlling the morphology and surface properties of the particles. ${ }^{9-11}$ Reetz and Halbig ${ }^{12}$ demonstrated how to produce and control the size of metal nanoparticles by electrochemical methods. Utilizing a fourelectrode arrangement, metal particles of copper and silver were deposited at the interface between two immiscible electrolyte solution. ${ }^{13}$ Cheng and Schiffrin ${ }^{14}$ have reported more recently on the formation of gold nanoparticles, whereas the electrodeposition of palladium at the $\mathrm{L}-\mathrm{L}$ interface has been studied by Johans et al. ${ }^{15-17}$ Recently a procedure has been reported for the preparation of polymer-coated silver nanoparticles at the $\mathrm{L}-\mathrm{L}$ interface. ${ }^{18}$ Whereas there are numerous reports on the catalytic activities of colloid metal particles dispersed in a single

* Corresponding author. E-mail: valentin@iunona.pmf.ukim.edu.mk.

$\dagger$ Sts. Cyril and Methodius University.

$\doteqdot$ Universidade do Porto. phase, ${ }^{1}$ studies on the catalytic properties of metal particles deposited at the $\mathrm{L}-\mathrm{L}$ interface are scarce. ${ }^{19,20}$

In the present communication a novel electrochemical method for deposition and voltammetric inspection of $\mathrm{Ag}$ particles at the water-nitrobenzene $(\mathrm{W}-\mathrm{NB})$ interface is proposed by virtue of thin-film electrodes. The electrode assembly consists of a graphite electrode (GE) covered with a thin NB film, containing decamethylferrocene (DMFC) as a redox probe. This electrode assembly, together with three-phase electrodes with immobilized droplets, ${ }^{21}$ has been widely used to study the electron transfer across the $\mathrm{L}-\mathrm{L}$ interface, ${ }^{22-24}$ as well as to measure thermodynamics $^{25-33}$ and kinetics ${ }^{34-37}$ of the ion transfer. The overall electrochemical process at the thin-film electrode proceeds as a combined electron-ion charge-transfer reaction, coupling the electron transfer at the GE-NB interface with the ion transfer across the $\mathrm{W}-\mathrm{NB}$ interface. It is expected that metal particles deposited at the $\mathrm{L}-\mathrm{L}$ interface of the thin-film electrode will affect the ion transfer, hence influencing the voltammetric response of the electrode. This is the basis for voltammetric inspection of the metal particles deposited at the $\mathrm{L}-\mathrm{L}$ interface of the thin-film electrode.

In the present study, two different strategies for deposition of $\mathrm{Ag}$ particles at the $\mathrm{W}-\mathrm{NB}$ interface of the thin-film electrode have been applied. In the first one, the deposition has been 
carried out under open circuit conditions by immersing the thinfilm electrode into an aqueous $\mathrm{AgNO}_{3}$ solution. As a consequence, a spontaneous heterogeneous electron-transfer reactions between $\mathrm{DMFC}_{(\mathrm{NB})}$ and $\mathrm{Ag}^{+}{ }_{(\mathrm{w})}$ occurs, resulting in formation of $\mathrm{Ag}$ particles deposited at the $\mathrm{W}-\mathrm{NB}$ interface. The presence of $\mathrm{Ag}$ particles at the $\mathrm{W}-\mathrm{NB}$ interface was evidenced by atomic force microscopy (AFM). Following the open circuit deposition step, the electrode has been transferred into an aqueous electrolyte to inspect the effect of the Ag deposit on the voltammetric response of the electrode. In the second protocol, i.e., controlled potential deposition, $\mathrm{Ag}^{+}$ions were present in the aqueous electrolyte and the deposition process was controlled voltammetrically by cycling of the electrode potential. In this procedure, the reactant in the organic phase (DMFC) is electrochemically regenerated in the thin film of the electrode, hence enabling continuation of the heterogeneous redox reaction between $\mathrm{DMFC}_{(\mathrm{NB})}$ and $\mathrm{Ag}^{+}(\mathrm{W})$. In the overall controlled potential deposition mechanism, by shuttling electrons from the electrode to the $\mathrm{L}-\mathrm{L}$ interface, the redox probe (DMFC) serves as a mediator for electrochemical reduction of $\mathrm{Ag}^{+}(\mathrm{W})$ at the $\mathrm{W}-\mathrm{NB}$ interface.

Voltammetric response of the thin-film electrode is strongly sensitive to the presence of $\mathrm{Ag}$ particles at the $\mathrm{W}-\mathrm{NB}$ interface. The overall voltammetric properties of the system depend strongly on the deposition protocol, reflecting the differences in the properties of the metal deposit. More importantly, after modification of the $\mathrm{W}-\mathrm{NB}$ interface with metal particles, additional heterogeneous electron-transfer reactions can be studied in order to inspect the catalytic properties of the metal particle-modified $\mathrm{L}-\mathrm{L}$ interface. This is evidenced by studying the heterogeneous electron exchange reactions between DM$\mathrm{FC}_{(\mathrm{NB})}$ and both $\left[\mathrm{Fe}(\mathrm{CN})_{6}\right]^{3-}$ (W) and $\mathrm{H}_{2} \mathrm{O}_{2(\mathrm{~W})}$ in the presence of Ag particles. In addition, this simple methodology can be utilized for preparation of novel metal particle modified thin organic film electrodes with potential applications in sensor technology.

\section{Experimental Section}

All chemicals used were of analytical grade purity. DMFC was purchased from Fluka. Other chemicals were Merck products. Water saturated NB was used to prepare the DMFC solution. In some experiments, the $\mathrm{NB}$ solution contained 0.1 $\mathrm{mol} / \mathrm{L}\left(\mathrm{C}_{4} \mathrm{H}_{9}\right)_{4} \mathrm{NClO}_{4}\left(\mathrm{Bu}_{4} \mathrm{NClO}_{4}\right)$ as an electrolyte.

A graphite rod (black graphite, GrafTech, UCAR SNC, La Lechere France) with a diameter of $0.113 \mathrm{~cm}$ has been used as a working electrode. Before modification with the NB solution, the graphite electrode was abraded with $\mathrm{SiC}$ paper. Thereafter, ca. $0.25 \mu \mathrm{L}$ NB solution was imposed on the electrode surface, and the film was formed by spontaneous spreading. An Ag/ $\mathrm{AgCl}$ (sat. $\mathrm{KCl}$ ) was the reference, while a $\mathrm{Pt}$ wire served as a counter electrode. Square-wave voltammetry (SWV) and cyclic voltammetry (CV) were conducted using $\mu$ AUTOLAB II and AUTOLAB PSTAT 10 equipment (Eco-Chemie, Utrecht, Netherlands).

AFM measurements were carried out with a Molecular Imaging PicoLe AFM using a silicon cantilever/tip (Nanosensors, cantilever resonance frequency of $65-90 \mathrm{kHz})$. The measurements were performed in a tapping mode, and several scans were imaged on various spots. The images were scanned in topography, amplitude, and phase mode, with a resolution of $512 \times 512$ pixels. Mica slides with diameter of $20 \mathrm{~mm}$ were used as substrates, at which the Ag nanoparticles were synthesized following the open circuit deposition procedure. AFM images were taken for different concentration ratios $c(\mathrm{DM}$ $\left.\mathrm{FC}_{(\mathrm{NB})}\right) / c\left(\mathrm{Ag}^{+}{ }_{(\mathrm{w})}\right)$. In general, the smaller the ratio $c\left(\mathrm{DMFC}_{(\mathrm{NB})}\right) /$
$c\left(\mathrm{Ag}^{+}{ }_{(\mathrm{w})}\right)$ (i.e., $c\left(\mathrm{Ag}^{+}{ }_{(\mathrm{w})}\right)>c\left(\mathrm{DMFC}_{(\mathrm{NB})}\right)$, the bigger the average diameter of Ag particles.

For preparation of all aqueous solutions, Mili-Q water was used. All experiments have been performed at room temperature.

\section{Results}

3.1. Open Circuit Deposition. Figure 1A depicts typical cyclic voltammograms recorded with a thin-film electrode in contact with $0.1 \mathrm{~mol} / \mathrm{L} \mathrm{LiClO}_{4}$ aqueous electrolyte following open circuit Ag deposition for different deposition times. The main feature of voltammograms is the strong diminishing of the voltammetric response proportional to the deposition time. In addition, the peak potential separation also decreases slightly by increasing the deposition time. Corresponding experiments performed under conditions of SWV are shown in Figure 1B. The SW voltammetric behavior is consistent with that observed with CV. Interestingly, under conditions corresponding to curve 3 in Figure 1B, when the deposition time was sufficiently long, the voltammetric response of the electrode vanished completely and only the noise was recorded.

Figure 2 shows AFM images of Ag particles deposited at the $\mathrm{W}-\mathrm{NB}$ interface. The size of the particles depends mainly on the concentration ratio $\rho=c\left(\mathrm{DMFC}_{(\mathrm{NB})}\right) / c\left(\mathrm{Ag}^{+}{ }_{(\mathrm{w})}\right)$. In general, the smaller the $\rho$, the bigger the average size of the $\mathrm{Ag}$ particles. Figure $2 \mathrm{~A}$ shows an image of $\mathrm{Ag}$ particles corresponding to $\rho=10$. The average size of $\mathrm{Ag}$ particles is about $200 \mathrm{~nm}$. They aggregate in clusters that cover partly the $\mathrm{W}-\mathrm{NB}$ interface. Figure $2 \mathrm{~B}$ shows an image of an Ag deposit corresponding to the concentration ratio $\rho=1$. In this case, large Ag particles were synthesized, forming a dense Ag deposit at the $\mathrm{W}-\mathrm{NB}$ interface.

In a recent study, ${ }^{34}$ we have demonstrated that the overall coupled electron-ion transfer reaction at the thin-film electrode is controlled by the rate of the ion transfer across the $\mathrm{W}-\mathrm{NB}$ interface. Thus, it is particularly useful to inspect the kinetics of the overall reaction in the presence of Ag deposit. This analysis can provide information on the degree of influence of the Ag deposit on the ion transfer across the W-NB interface. For this purpose, cyclic voltammograms have been recorded in contact with $0.1 \mathrm{~mol} / \mathrm{L} \mathrm{LiClO}_{4}$ electrolyte solution at various scan rates prior to and following open circuit $\mathrm{Ag}$ deposition. In the absence of Ag particles, the peak potentials of both cathodic and anodic peaks of cyclic voltammograms are independent of the scan rate for $v \leq 300 \mathrm{mV} / \mathrm{s}$ (data not shown). On the contrary, in a presence of $\mathrm{Ag}$ deposit, the peak potential separation increases in proportion to the scan rate, even at moderate scan rates $\left(5 \leq v /\left(\mathrm{mV} \mathrm{s}^{-1}\right) \leq 60\right)$ (Figure $\left.3 \mathrm{~A}\right)$. This implies that the $\mathrm{Ag}$ deposit decreases significantly the rate of $\mathrm{ClO}_{4}{ }^{-}$transfer across the $\mathrm{W}-\mathrm{NB}$ interface and the overall electrochemical reaction at the thin-film electrode exhibits properties of a kinetically controlled process.

To inspect the kinetics with SWV, a recently introduced method based on the quasireversible maximum has been applied. ${ }^{34,36,37}$ This methodology requires inspection of the ratio $I_{\mathrm{p}} f^{-0.5}$ versus $\log (f)$, where $I_{\mathrm{p}}$ is the net SW peak current, and $f$ is the frequency of the SW potential modulation. This dependence has a parabolic shape. The position of the maximum is proportional to the rate of the ion transfer reaction. ${ }^{34,35,37}$ Figure 3B compares quasireversible maxima measured before and after modification of the $\mathrm{W}-\mathrm{NB}$ interface with Ag deposit. In the absence of $\mathrm{Ag}$ deposit, the critical frequency is $f_{\max }=$ $25 \mathrm{~Hz}$ (curve 1 in Figure 3B), whereas in the presence of $\mathrm{Ag}$ particles, only the descending part of the quasireversible maximum was observed (curve 2 in Figure 3B). This implies 

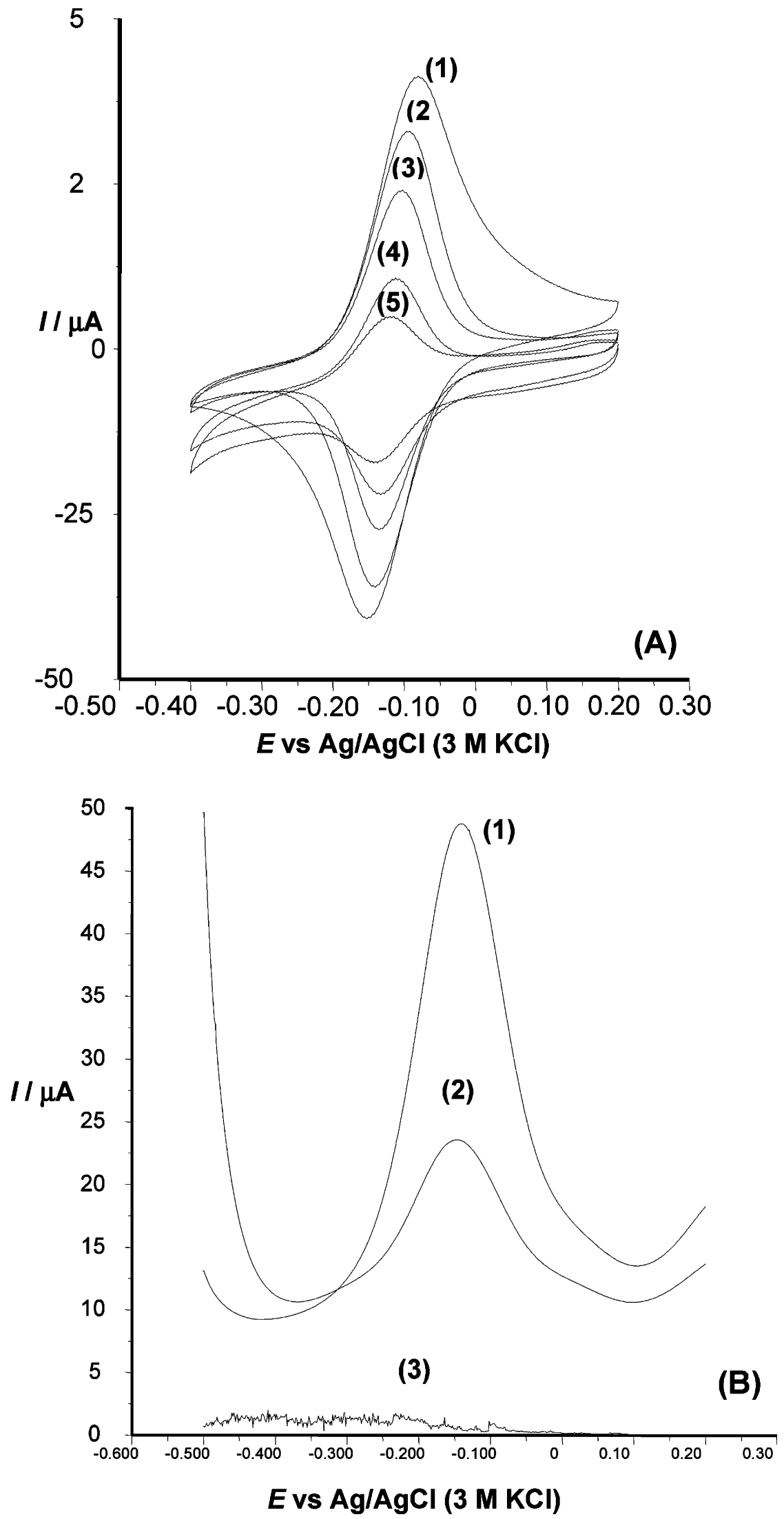

Figure 1. (A) Cyclic voltammograms recorded with a thin-film electrode in contact with a $0.1 \mathrm{~mol} / \mathrm{L} \mathrm{LiClO}_{4}$ aqueous solution following open circuit $\mathrm{Ag}$ deposition in $0.1 \mathrm{~mol} / \mathrm{L} \mathrm{AgNO}_{3}$ solution for 0 (1); 5 (2); $15(3) ; 45(4)$, and $100 \mathrm{~s} \mathrm{(5).} \mathrm{The} \mathrm{scan} \mathrm{rate} \mathrm{was} v=50 \mathrm{mV} / \mathrm{s}$. The NB film contained $10 \mathrm{mmol} / \mathrm{L} \mathrm{DMFC}$ and $0.1 \mathrm{~mol} / \mathrm{L} \mathrm{Bu}_{4} \mathrm{NClO}_{4}$. (B) Net SW voltammograms recorded with a thin-film electrode in contact with a 0.1 $\mathrm{mol} / \mathrm{L} \mathrm{LiClO}_{4}$ aqueous solution following open circuit $\mathrm{Ag}$ deposition in $10 \mathrm{mmol} / \mathrm{L} \mathrm{AgNO}_{3}$ solution for 0 (1); 2 (2), and $7 \mathrm{~min}$ (3). The $\mathrm{NB}$ film contained $5 \mathrm{mmol} / \mathrm{L}$ DMFC. Parameters of the potential modulation were: frequency $f=10 \mathrm{~Hz}$, amplitude $E_{\mathrm{sw}}=50 \mathrm{mV}$, and potential step $\mathrm{d} E$ $=1 \mathrm{mV}$. 


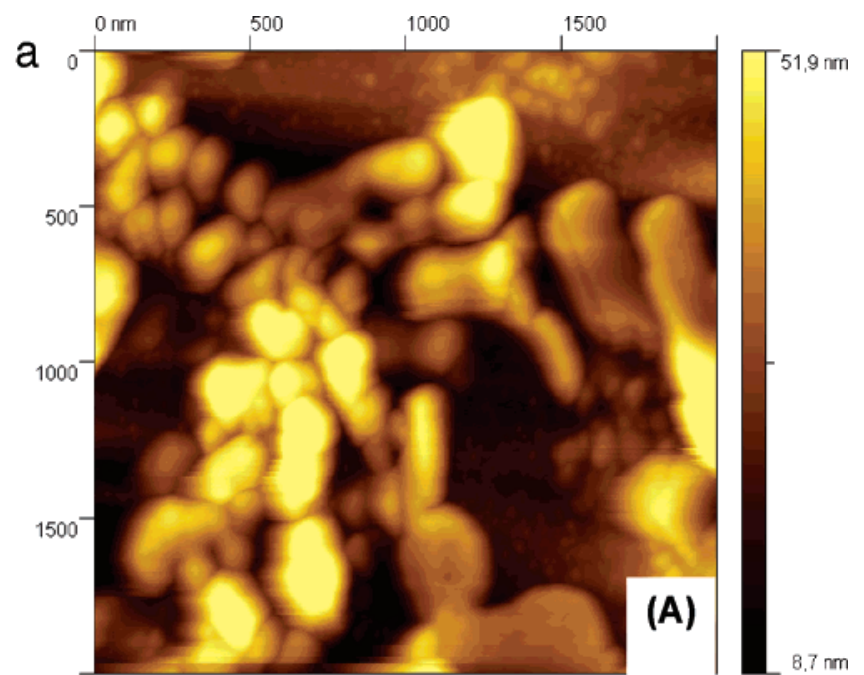

\section{$c\left(\mathrm{DMFC}_{(\mathrm{NB})}\right): c\left(\mathrm{Ag}^{+}{ }_{(\mathrm{w})}\right)=10: 1$}

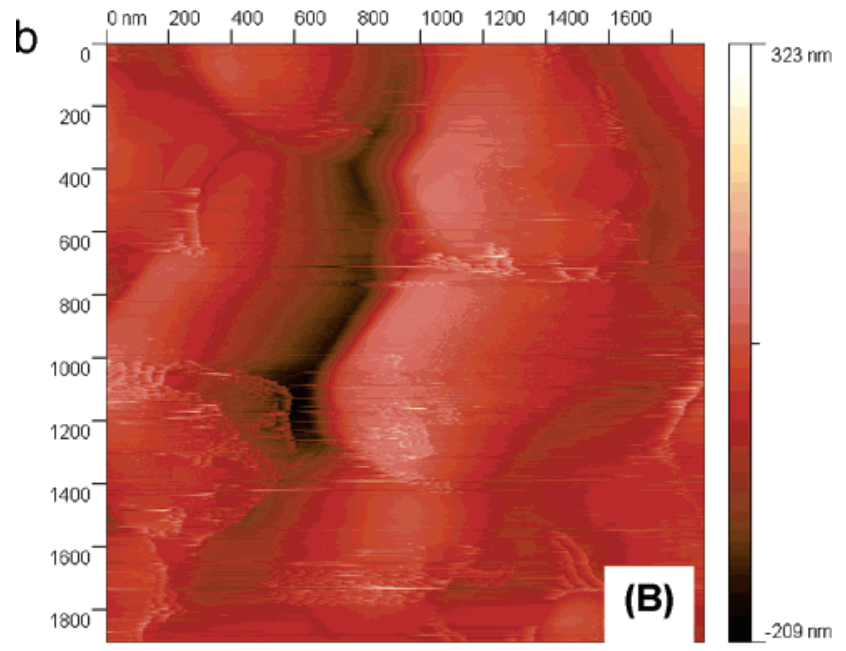

\section{$c\left(\mathrm{DMFC}_{(\mathrm{NB})}\right): c\left(\mathrm{Ag}^{+}(\mathrm{w})\right)=1: 1$}

Figure 2. AFM images of Ag particles deposited by open circuit procedure. The NB solution contained $1 \mathrm{mmol} / \mathrm{L}$ DMFC, and the aqueous phase contained $0.1 \mathrm{mmol} / \mathrm{L}$ and $1 \mathrm{mmol} / \mathrm{L} \mathrm{AgNO}_{3}$ for $(\mathrm{A})$ and for (B), respectively.

that the maximum is positioned at a frequency lower than 8 $\mathrm{Hz}$, i.e., the lowest frequency available with the used instrumentation. These results are in agreement with cyclic voltammetric measurements indicating that $\mathrm{Ag}$ particles deposit at the $\mathrm{W}-\mathrm{NB}$ interface impede significantly the ion transfer rate.

Contrary to the hindering effect toward the ion transfer, the Ag-deposit exhibits a profound effect toward electron transfer reactions across the $\mathrm{W}-\mathrm{NB}$ interface. This effect was studied following formation of a dense Ag film. Under such conditions, the ion transfer is completely prevented, resulting in vanishing of the voltammetric response of the electrode. However, the response of the electrode can be restored in the presence of redox compounds in the aqueous electrolyte, e.g., $\mathrm{K}_{3}\left[\mathrm{Fe}(\mathrm{CN})_{6}\right]$, which is capable of exchanging electrons with the organic redox probe. Figure 4A shows net SW voltammograms recorded with a thinfilm electrode modified with a dense Ag film in contact with $0.1 \mathrm{~mol} / \mathrm{L} \mathrm{LiClO}_{4}$ before (curve 1) and after (curve 2) addition of $\mathrm{K}_{3}\left[\mathrm{Fe}(\mathrm{CN})_{6}\right]$ to the aqueous electrolyte. Figure $4 \mathrm{~B}$ shows a typical cyclic voltammogram of the same type of electrode recorded in contact with an aqueous electrolyte containing $\mathrm{K}_{3}$ $\left[\mathrm{Fe}(\mathrm{CN})_{6}\right]$. The shape of voltammograms is typical for a reductive catalytic mechanism in which the initial reactant is chemically regenerated in the course of the voltammetric experiment. It should be also noted that by repetitive cycling of the potential, stable cyclic voltammograms have been obtained. In addition, the response of this type of electrode increases in proportion to the concentration of $\left[\mathrm{Fe}(\mathrm{CN})_{6}\right]^{3-}(\mathrm{W})$. Over the concentration interval $1<c\left(\left[\mathrm{Fe}(\mathrm{CN})_{6}\right]^{3-}\right) / \mathrm{mmol} \mathrm{L}^{-1}$ $<4$, the dependence of the net SW peak currents $\left(I_{\mathrm{p}}\right)$ versus $\log c\left(\left[\mathrm{Fe}(\mathrm{CN})_{6}\right]^{3-}\right)$ is linear with a slope of $2.38(R=0.969)$. On the contrary, in the absence of an Ag deposit, the net SW peak current decreases by increasing $c\left(\left[\mathrm{Fe}(\mathrm{CN})_{6}\right]^{3-}\right)$, and the dependence $I_{\mathrm{p}}$ vs $\log c\left(\left[\mathrm{Fe}(\mathrm{CN})_{6}\right]^{3-}\right)$ has a negative slope of $-0.15(R=0.999)$. This implies that the heterogeneous electron exchange reaction between $\mathrm{DMFC}_{(\mathrm{NB})}$ and $\left[\mathrm{Fe}(\mathrm{CN})_{6}\right]^{3-}(\mathrm{W})$ in the absence of Ag particles is, most likely, accompanied by complex interfacial phenomena such as a homogeneous electrontransfer reaction and precipitation of a salt of $\mathrm{DMFC}^{+}(\mathrm{NB})$ and the $\left[\mathrm{Fe}(\mathrm{CN})_{6}\right]^{4-}$ (W) counterion.

3.2. Controlled Potential Deposition. Figure 5A represents the effect of the deposition time on the net SW voltammograms during controlled potential deposition protocol. These experiments have been performed by recording repetitive SW voltammograms with a single thin-film electrode in contact with an aqueous solution containing $0.1 \mathrm{~mol} / \mathrm{L} \mathrm{NaClO}_{4}$ and $1 \mathrm{mmol} / \mathrm{L}$ $\mathrm{AgNO}_{3}$. A significant increase of the current with deposition time is evident, which is opposite to the corresponding effect observed in the open circuit deposition protocol. In addition to the variation of the net peak current, the peak potential and halfpeak width of the SW voltammograms do not vary significantly with deposition time. It is an interesting observation that, after a certain deposition period, the net peak current reaches a constant value. As shown in the inset of Figure 5A, the dependence of the net SW peak current versus deposition time has a shape of an isotherm. The slope of the rising portion of the isotherm is proportional to the concentration of $\mathrm{Ag}^{+}(\mathrm{W})$ ions. Moreover, the higher the concentration of $\mathrm{Ag}^{+}$(W) ions the shorter the deposition time to reach saturation level.

To provide a deeper insight into the properties of the overall mechanism, Figure 5B depicts the forward (oxidation) and backward (reduction) components of the SW voltammograms recorded at different deposition times. Obviously, the increase of the net SW peak with deposition time is a consequence of proportional increase of both components of the response (Figure 5B). All other properties of the response, such as half-peak width and peak potential of both forward and backward components of the SW response are independent of the deposition time.

Under conditions of $\mathrm{CV}$, the results for controlled potential Ag deposition are consistent with those observed with SWV. Figure 6 shows repetitive cyclic voltammograms recorded in contact with $0.1 \mathrm{~mol} / \mathrm{L} \mathrm{NaClO}_{4}$ aqueous solution containing 0.2 $\mathrm{mmol} / \mathrm{L} \mathrm{AgNO}_{3}$. Both anodic and cathodic components of the $\mathrm{CV}$ voltammograms increase in proportion to the deposition time.

In addition to concentrations of $\mathrm{DMFC}_{(\mathrm{NB})}$ and $\mathrm{Ag}^{+}(\mathrm{W})$, the rate of $\mathrm{Ag}$ deposition is expected to be dependent on the potential difference at the $\mathrm{W}-\mathrm{NB}$ interface, defined as $\Delta_{\mathrm{W}}^{\mathrm{NB}} \phi$ $=\phi_{\mathrm{NB}}-\phi_{\mathrm{W}}$, where $\phi$ is the symbol for the inner potential. To inspect this effect, two sets of experiments have been conducted. In the first one, the deposition was studied by using NB solution containing $0.1 \mathrm{~mol} / \mathrm{L} \mathrm{Bu}_{4} \mathrm{NClO}_{4}$ in contact with $0.1 \mathrm{~mol} / \mathrm{L}$ $\mathrm{KClO}_{4}$ aqueous solution. In this case, the potential difference is controlled by the concentrations of the common $\mathrm{ClO}_{4}{ }^{-}$ions 

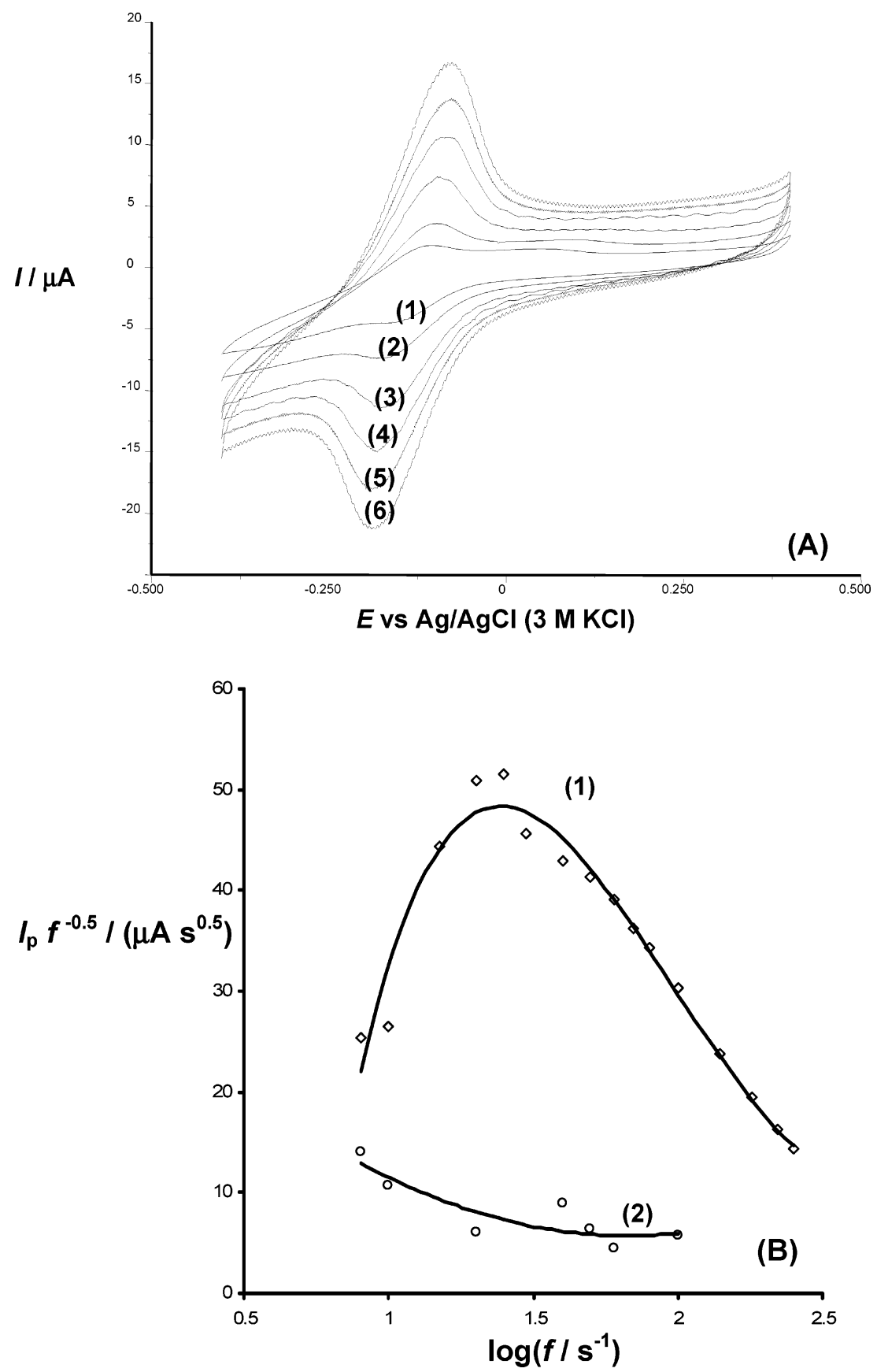

Figure 3. (A) Effect of the scan rate on the cyclic voltammograms of an open circuit Ag-modified thin-film electrode measured in contact with a $0.1 \mathrm{~mol} / \mathrm{L} \mathrm{LiClO}_{4}$ aqueous solution. The scan rates were: 5 (1); 10 (2); 20 (3); 30 (4); 40 (5); and $60 \mathrm{mV} / \mathrm{s}$ (6). (B) Quasireversible maxima recorded with a thin-film electrode (1) and open circuit Ag-modified thin-film electrode (2) in contact with a $0.1 \mathrm{~mol} / \mathrm{L} \mathrm{LiClO}{ }_{4}$ aqueous solution. For both (A) and (B) the NB solution contained $10 \mathrm{mmol} / \mathrm{L} \mathrm{DMFC}$ and $0.1 \mathrm{~mol} / \mathrm{L} \mathrm{Bu}_{4} \mathrm{NClO}_{4}$. The thin-film electrode was modified for $1 \mathrm{~min}$ in $10 \mathrm{mmol} / \mathrm{L} \mathrm{AgNO}_{3}$ solution. Parameters of the $\mathrm{SW}$ potential modulation were the same as for Figure $1 \mathrm{~B}$.

present in both liquid phases. As $c\left(\mathrm{ClO}_{4}{ }^{-}(\mathrm{W})\right)=c\left(\mathrm{ClO}_{4}{ }^{-}{ }_{(\mathrm{NB})}\right)$, the potential difference is equal to the standard potential of $\mathrm{ClO}_{4}{ }^{-}$transfer from water to nitrobenzene, which is $80 \mathrm{mV} .^{32}$ In the second set of experiments, the NB did not contain any deliberately added electrolyte. Hence, in this case, the potential difference was controlled by the partition of the aqueous electrolyte. For partitioning of a single salt, MX, between two immiscible solvents, the potential difference is defined as $\Delta_{\mathrm{W}}{ }^{\mathrm{NB}} \phi$ $=1 / 2\left(\Delta^{\mathrm{W} \rightarrow \mathrm{NB}} \phi_{\mathrm{X}^{-}}^{0}+\Delta^{\mathrm{W} \rightarrow \mathrm{NB}} \phi_{\mathrm{M}^{+}}^{0}\right){ }^{38}$ Using $\mathrm{KClO}_{4}$ as a partitioning salt, the potential difference was $-74 \mathrm{mV} .{ }^{32}$ Figure 7 shows the variation of the $\mathrm{Ag}$ deposition rate with time for these two sets of experiments. The ordinate displays the rate defined as $v=\Delta I_{\mathrm{p}} / \Delta t$, where $\Delta I_{\mathrm{p}}$ is the difference in the net $\mathrm{SW}$ peak currents between two measurements and $\Delta t$ is the time between these measurements. The dependence $v$ vs. $t$ has a parabolic shape, associated with a maximum positioned at certain critical time. The descending part of the dependence reflects the commencement of the saturation process of the interface with an Ag deposit. Curve 2, corresponding to $\Delta_{\mathrm{W}}^{\mathrm{NB}} \phi=-74 \mathrm{mV}$, is attributed with a more pronounced maximum that is positioned at shorter deposition time.

Catalytic activity of the controlled potential deposited $\mathrm{Ag}$ particles has been examined by studying heterogeneous electrontransfer reactions between $\mathrm{DMFC}_{(\mathrm{NB})}$ and $\mathrm{H}_{2} \mathrm{O}_{2}(\mathrm{~W})$. Figure 8 summarizes the results measured in the presence of $\mathrm{H}_{2} \mathrm{O}_{2}(\mathrm{~W})$. Figure $8 \mathrm{~A}$ shows cyclic voltammograms recorded in contact 

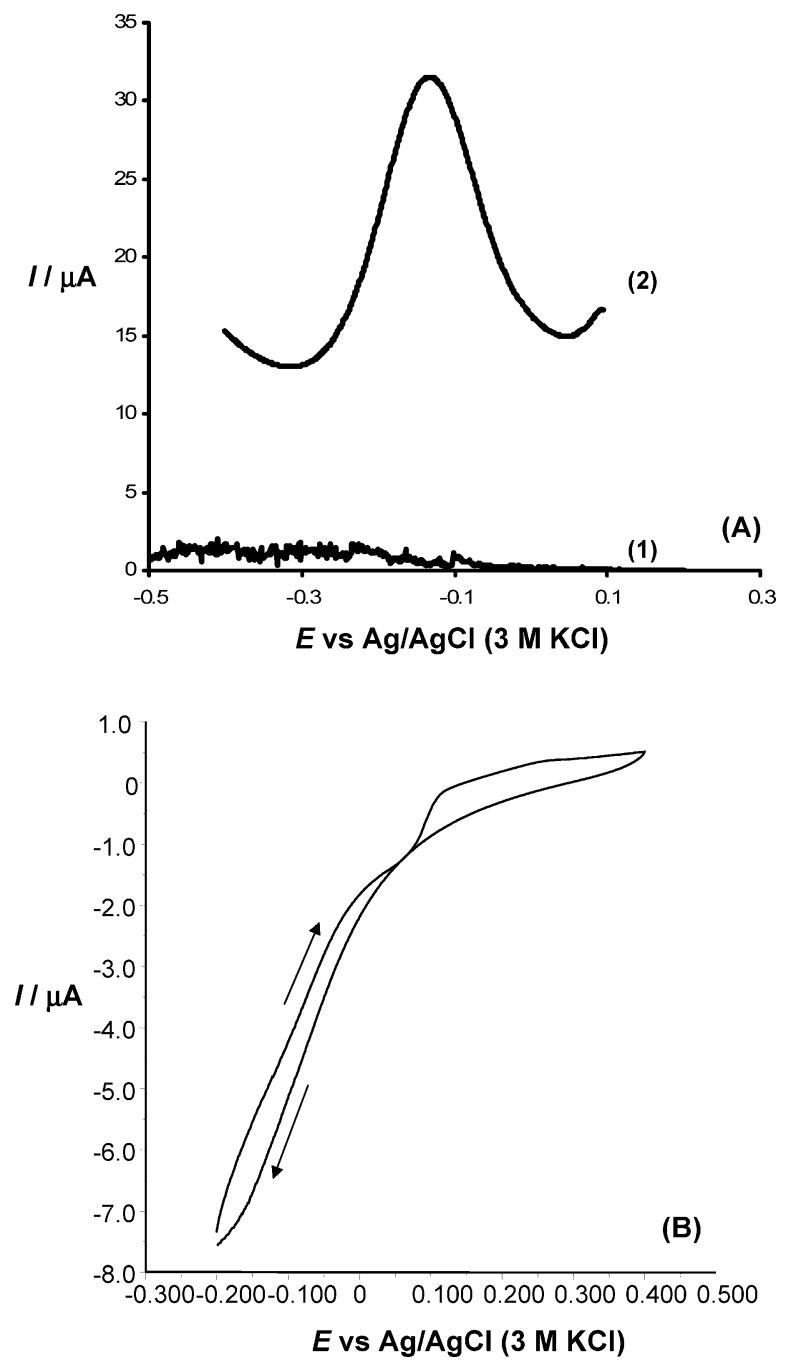

Figure 4. (A) Net $\mathrm{SW}$ voltammograms recorded with a thin-film electrode modified with a dense $\mathrm{Ag}$ film in contact with a $0.1 \mathrm{~mol} / \mathrm{L}$ $\mathrm{LiClO}_{4}(1)$ and $0.1 \mathrm{~mol} / \mathrm{L} \mathrm{LiClO}_{4}+5 \mathrm{mmol} / \mathrm{L} \mathrm{K}_{3}\left[\mathrm{Fe}(\mathrm{CN})_{6}\right]$ (2) aqueous solutions. The electrode was modified with $\mathrm{Ag}$ deposit at an open circuit in a $10 \mathrm{mmol} / \mathrm{L} \mathrm{AgNO}_{3}$ aqueous solution for $7 \mathrm{~min}$. The NB film contained $5 \mathrm{mmol} / \mathrm{L}$ DMFC. (B) Cyclic voltammogram recorded with a thin-film electrode at a scan rate of $0.5 \mathrm{mV} / \mathrm{s}$ following complete blocking of the $\mathrm{W}-\mathrm{NB}$ interface with a dense $\mathrm{Ag}$ film in contact with an aqueous electrolyte containing $0.1 \mathrm{~mol} / \mathrm{L} \mathrm{LiClO}_{4}$ and $10 \mathrm{mM} \mathrm{K}_{3-}$ $\left[\mathrm{Fe}(\mathrm{CN})_{6}\right]$. The NB film contained $10 \mathrm{mmol} / \mathrm{L} \mathrm{DMFC}$ and $0.1 \mathrm{~mol} / \mathrm{L}$ $\mathrm{Bu}_{4} \mathrm{NClO}_{4}$.

with $0.05 \mathrm{~mol} / \mathrm{L} \mathrm{KClO}_{4}$ aqueous solution containing an acetate buffer at $\mathrm{pH}=4$.7. Curve 1 is measured in the absence of $\mathrm{H}_{2} \mathrm{O}_{2}$, whereas curve 2 is measured in the presence of $23 \mathrm{mmol} / \mathrm{L}$ $\mathrm{H}_{2} \mathrm{O}_{2}$. Curve 3 is recorded after controlled potential modification of the thin-film electrode with Ag deposit, in contact with the same aqueous solution as for curve 2 . The catalytic nature of the electrode mechanism for both curves 2 and 3 is obvious. Apparently, the $\mathrm{Ag}$ deposit enhances strongly the effect of $\mathrm{H}_{2} \mathrm{O}_{2}$, which increases dramatically the reduction current as well as the potentials at which the reduction of $\mathrm{H}_{2} \mathrm{O}_{2}$ commences.

Figure $8 \mathrm{~B}$ shows the effect of $\mathrm{H}_{2} \mathrm{O}_{2(\mathrm{~W})}$ concentration measured with a thin-film electrode (curve 1) and thin-film electrode following controlled potential Ag deposition (curve 2). The slope of curve 2 is more than one order of magnitude higher than the slope of curve 1, confirming the strong catalytic effect of the Ag particle modified thin film electrode toward the rate of the electron exchange reaction between $\mathrm{DMFC}_{(\mathrm{NB})}$ and $\mathrm{H}_{2} \mathrm{O}_{2(\mathrm{~W})}$.
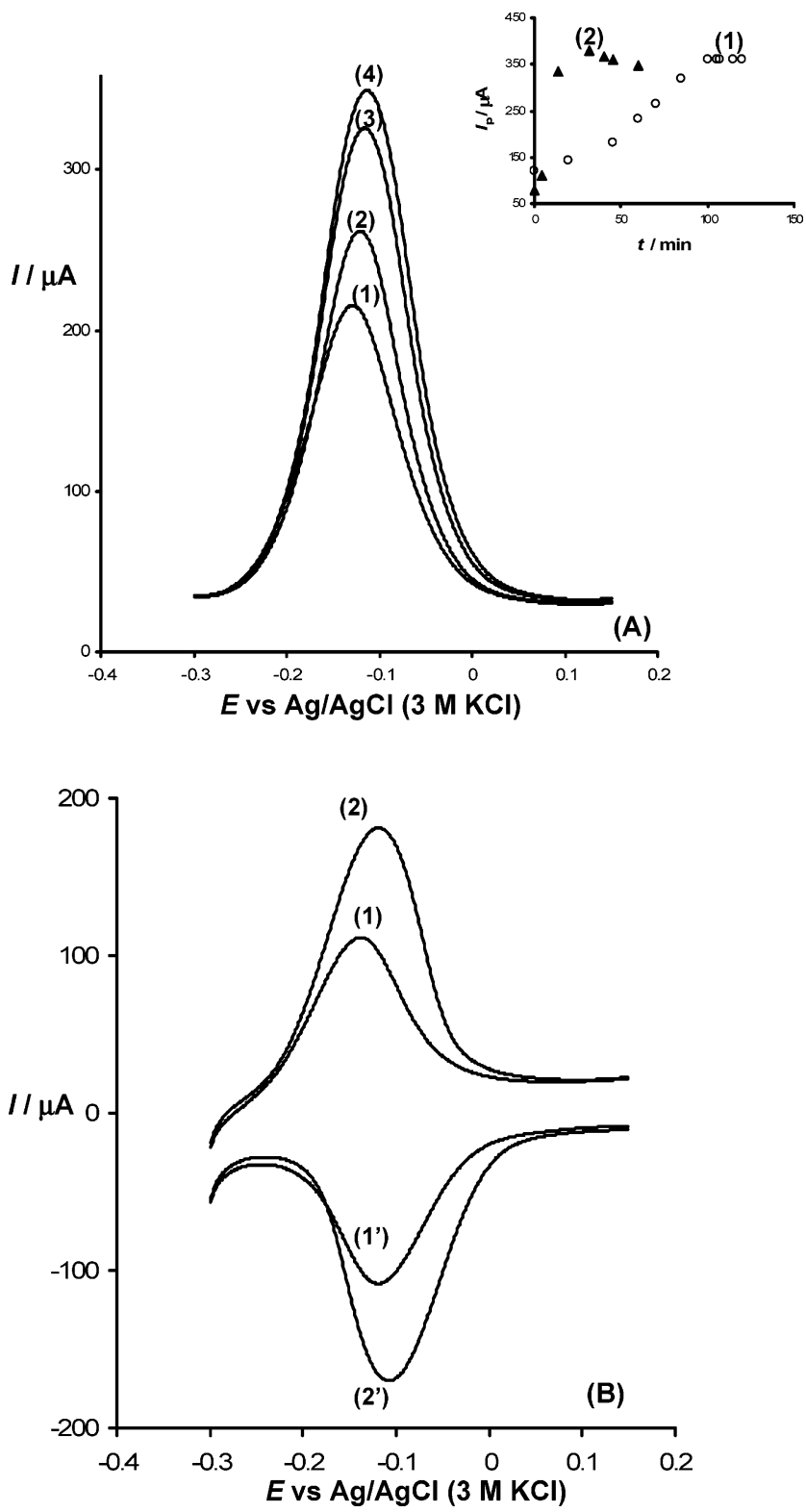

Figure 5. 5. (A) Net $\mathrm{SW}$ voltammograms recorded at different times during controlled potential deposition protocol in contact with an aqueous solution containing $0.1 \mathrm{~mol} / \mathrm{L} \mathrm{KClO}_{4}$ and $1 \mathrm{mmol} / \mathrm{L}^{\mathrm{AgNO}_{3}}$. The deposition time was: 0 (1); 20 (2); 50 (3); and $70 \mathrm{~min}$ (4). The NB film contained $10 \mathrm{mmol} / \mathrm{L}$ DMFC. The inset shows the dependence of the net SW peak current on the deposition time corresponding to 1 $\mathrm{mmol} / \mathrm{L} \mathrm{(1)} \mathrm{and} 10 \mathrm{mmol} / \mathrm{L}$ concentrations of $\mathrm{AgNO}_{3}$ in the aqueous electrolyte. The NB film contained $10 \mathrm{mmol} / \mathrm{L}$ DMFC and $0.1 \mathrm{~mol} / \mathrm{L}$ $\mathrm{Bu}_{4} \mathrm{NClO}_{4}$. (B) Forward (curves 1 and 2) and backward (curves 1' and $2^{\prime}$ ) components of SW voltammetric responses recorded after deposition time of $0\left(1\right.$ and $\left.1^{\prime}\right)$ and 70 min $\left(2\right.$ and $\left.2^{\prime}\right)$. All other conditions are the same as for (A). Parameters of the SW potential modulation were the same as for Figure 1B.

\section{Discussion}

The voltammetric response of the thin-film electrode recorded in contact with an aqueous electrolytes containing $\mathrm{ClO}_{4}{ }^{-}$or $\mathrm{NO}_{3}{ }^{-}$ions is described by the following overall reaction:

$$
\mathrm{DMFC}_{(\mathrm{NB})}+\mathrm{X}_{(\mathrm{W})}^{-}=\mathrm{DMFC}_{(\mathrm{NB})}^{+}+\mathrm{X}_{(\mathrm{NB})}^{-}+\mathrm{e}
$$

where $\mathrm{X}^{-}$is a symbol for corresponding anion. This process causes curve 1 in both Figs $1 \mathrm{~A}$ and $1 \mathrm{~B}$. The overall process (reaction I) couples two simultaneous charge-transfer reactions 


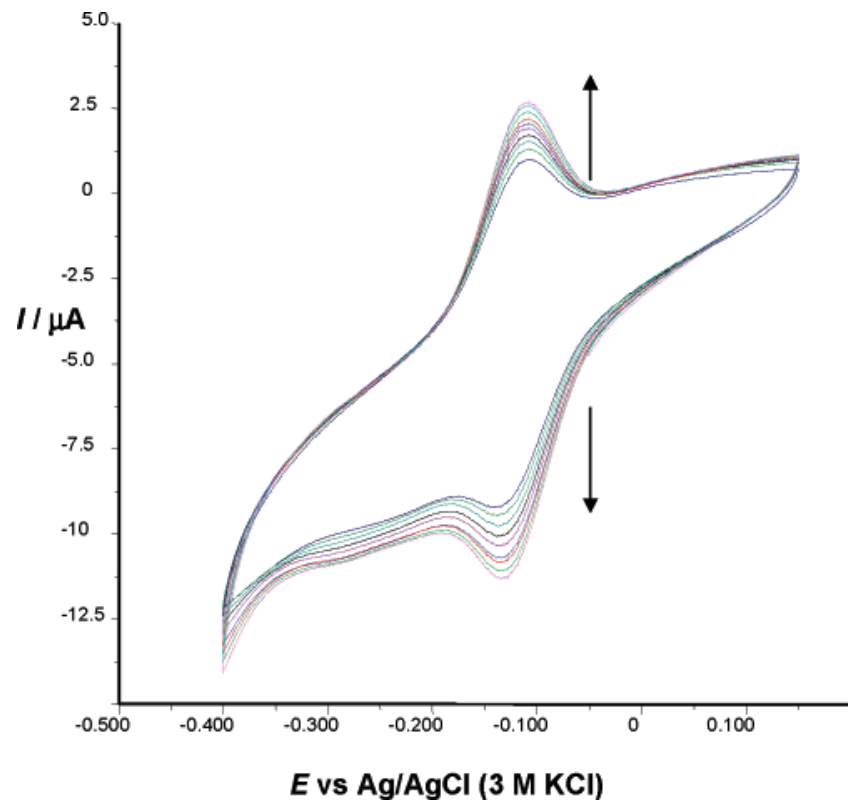

Figure 6. 6. Subsequent cyclic voltammograms recorded with a thinfilm electrode at a scan rate of $v=50 \mathrm{mV} / \mathrm{s}$ in contact with an aqueous solution containing $0.1 \mathrm{~mol} / \mathrm{L} \mathrm{LiClO}_{4}$ and $0.2 \mathrm{mmol} / \mathrm{L} \mathrm{AgNO}_{3}$. The $\mathrm{NB}$ film contained $10 \mathrm{mmol} / \mathrm{L} \mathrm{DMFC}$ and $0.1 \mathrm{~mol} / \mathrm{L} \mathrm{Bu}_{4} \mathrm{NClO}_{4}$. The direction of arrows shows the increasing number of subsequent scans.

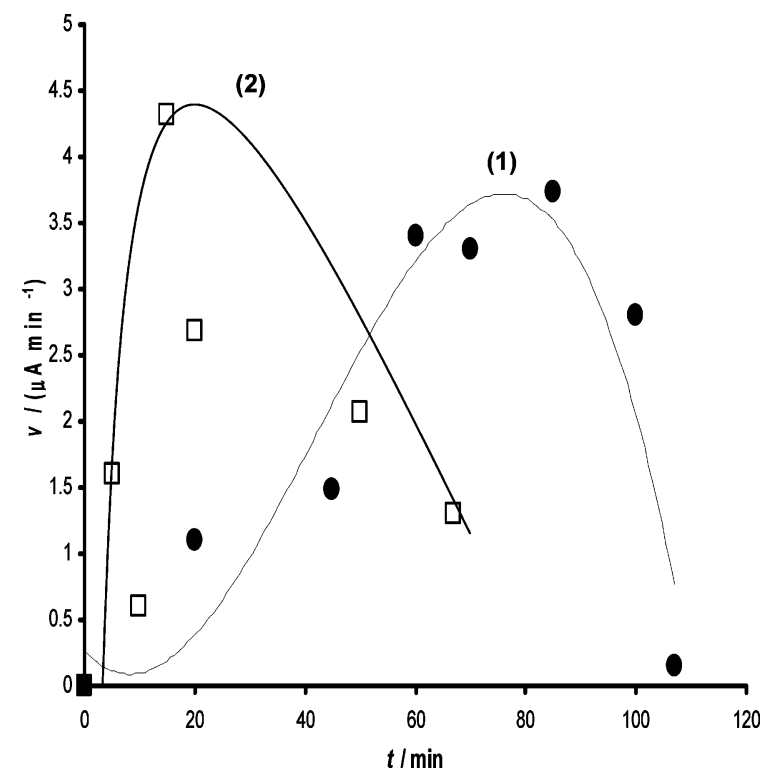

Figure 7. 7. Dependence of the rate of net SW peak current increasing on time during controlled potential deposition recorded with a thinfilm electrode in contact with an aqueous solution containing $0.1 \mathrm{~mol} / \mathrm{L}$ $\mathrm{KClO}_{4}$ and $1 \mathrm{mmol} / \mathrm{L} \mathrm{AgNO}_{3}$. The $\mathrm{NB}$ film contained $10 \mathrm{mmol} / \mathrm{L}$ DMFC and $0.1 \mathrm{~mol} / \mathrm{L} \mathrm{Bu}_{4} \mathrm{NClO}_{4}$ for curve (1) and $10 \mathrm{mmol} / \mathrm{L} \mathrm{DMFC}$ for curve (2). The rate is defined as $v=\Delta I_{\mathrm{p}} / \Delta t$, where $\Delta I_{\mathrm{p}}$ is the difference in the net SW peak currents between two measurements and $\Delta t$ is the time between these measurements. Parameters of the potential modulation were the same as for Figure 1B

occurring at separate interfaces; that is, the electron transfer at $\mathrm{GE}-\mathrm{NB}$ (reaction II) and the ion transfer at the $\mathrm{W}-\mathrm{NB}$ interface (reaction III):

$$
\begin{gathered}
\mathrm{DMFC}_{(\mathrm{NB})}=\mathrm{DMFC}_{(\mathrm{NB})}^{+}+\mathrm{e}(\mathrm{GE}-\mathrm{NB}) \\
\mathrm{X}_{(\mathrm{W})}^{-}=\mathrm{X}_{(\mathrm{NB})}^{-}(\mathrm{W}-\mathrm{NB})
\end{gathered}
$$

Therefore, phenomena that take place at the $\mathrm{W}-\mathrm{NB}$ interface and affect the ion transfer reaction III can be voltammetrically detected.
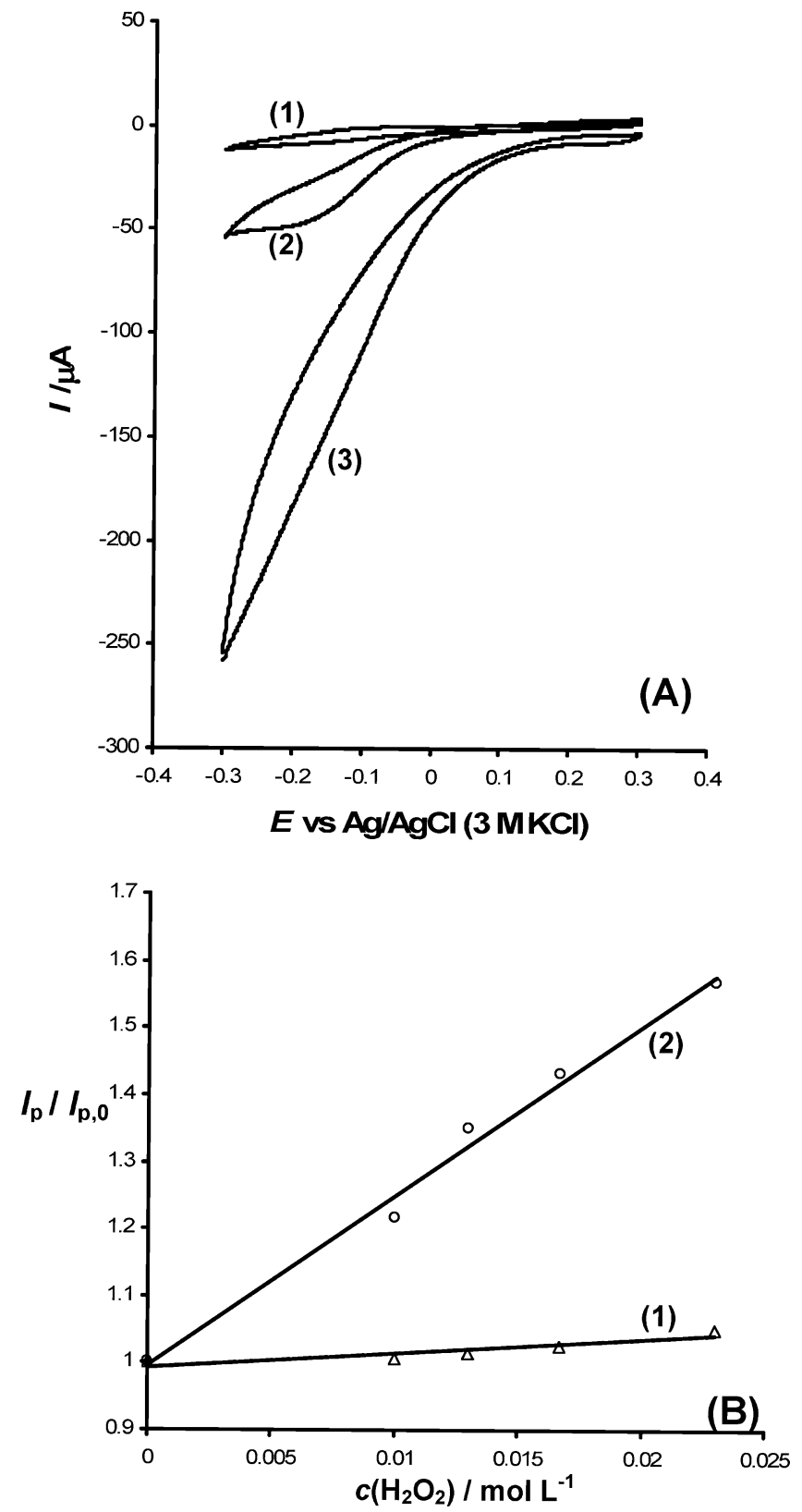

Figure 8. 8. (A) Effect of $\mathrm{H}_{2} \mathrm{O}_{2}$ on the cyclic voltammetric response of a thin-film electrode recorded in contact with $0.05 \mathrm{~mol} / \mathrm{L}$ acetate buffer at $\mathrm{pH}=4.7$ containing $0.05 \mathrm{~mol} / \mathrm{L} \mathrm{KClO}_{4}$. Concentration of $\mathrm{H}_{2} \mathrm{O}_{2}$ was $0 \mathrm{~mol} / \mathrm{L}$ for curve 1 and $23 \mathrm{mmol} / \mathrm{L}$ for curves 2 and 3 . Curve 3 is recorded after controlled potential Ag deposition for $64 \mathrm{~min}$. Scan rate was $v=20 \mathrm{mV} / \mathrm{s}$. (B) Dependence of the ratio $I_{\mathrm{p}} / I_{\mathrm{p}, 0}$ on the concentration of $\mathrm{H}_{2} \mathrm{O}_{2}$ for the thin-film electrode (1) and controlled potential Ag modified thin-film electrode (2). $I_{\mathrm{p}}$ is the net $\mathrm{SW}$ peak current at a corresponding concentration of $\mathrm{H}_{2} \mathrm{O}_{2}$ and $I_{\mathrm{p}, 0}$ is the net peak current in the absence of $\mathrm{H}_{2} \mathrm{O}_{2}$. Parameters of the potential modulation were the same as for Figure 1B. For both (A) and (B), controlled potential Ag-deposition was performed in $0.1 \mathrm{~mol} / \mathrm{L} \mathrm{KClO}_{4}$ solution containing $0.1 \mathrm{mmol} / \mathrm{L} \mathrm{AgNO}_{3}$. The $\mathrm{NB}$ film contained 10 $\mathrm{mmol} / \mathrm{L} \mathrm{DMFC}$ and $0.1 \mathrm{~mol} / \mathrm{L} \mathrm{Bu}_{4} \mathrm{NClO}_{4}$.

During open circuit deposition, immersing the thin-film electrode in an $\mathrm{AgNO}_{3}$ aqueous solution enables the spontaneous heterogeneous redox reaction between $\mathrm{DMFC}_{(\mathrm{NB})}$ and $\mathrm{Ag}^{+}(\mathrm{W})$ to proceed, resulting in an $\mathrm{Ag}$ deposit at the $\mathrm{W}-\mathrm{NB}$ interface. The process is described by following scheme:

$$
\begin{aligned}
\mathrm{Ag}_{(\mathrm{W})}^{+}+\mathrm{DMFC}_{(\mathrm{NB})}+\mathrm{X}_{(\mathrm{W})}^{-} \rightarrow \mathrm{Ag}_{(\mathrm{s})}+\mathrm{DMFC}_{(\mathrm{NB})}^{+}+ \\
\mathrm{X}_{(\mathrm{NB})}^{-}(\mathrm{W}-\mathrm{NB})(\mathrm{IV})
\end{aligned}
$$


Note that, due to electroneutrality reasons, reaction IV has to include transfer of anion from water to nitrobenzene. The decrease of the voltammetric response in Figure 1 is a consequence of a blocking effect of the $\mathrm{W}-\mathrm{NB}$ interface with silver particles that diminishes the active surface area of the $\mathrm{W}-\mathrm{NB}$ interface for ion transfer reaction III. Additionally, the colloid Ag particles, deposited at the $\mathrm{W}-\mathrm{NB}$ interface, hinder the rate of the ionic transfer or increase the ohmic resistance of the ionic current. It is also probable that both effects are simultaneously present. For these reasons, the peak potential separation of cyclic voltammograms increases in proportion to the scan rate (Figure 3A). Kinetic measurements with SWV are in favor of the kinetic effect. As elaborated in detail in a series of previous studies, ${ }^{34-37}$ the dependence $I_{\mathrm{p}} f^{-0.5}$ versus $\log (f)$ (Figure 3B) in thin-film voltammetry is a parabolic curve, known as a quasi-reversible maximum. The position of the maximum is proportional to the standard rate constant of the electrochemical process. ${ }^{36}$ In addition, the kinetics of the coupled electronion transfer reaction I at a thin-film electrode is controlled by the rate of the ion transfer III. ${ }^{34,35,37}$ Hence, curve 1 in Figure $3 \mathrm{~B}$, measured in the absence of $\mathrm{Ag}$ deposit, is a quasi-reversible maximum for the transfer of $\mathrm{ClO}_{4}{ }^{-}$across the $\mathrm{W}-\mathrm{NB}$ interface, which is associated with a critical frequency of about $25 \mathrm{~Hz}$, corresponding to the standard rate constant of $8 \times 10^{-3} \mathrm{~cm}$ $\mathrm{s}^{-1} .{ }^{37}$ In the presence of $\mathrm{Ag}$ deposit, only the descending part of the quasi-reversible maximum was measured (curve 2 in Figure $3 \mathrm{~B}$ ), indicating that the maximum is positioned at a frequency lower than $8 \mathrm{~Hz}$, i.e., the lowest frequency available by the instrumentation. For this reason, the transfer of $\mathrm{ClO}_{4}{ }^{-}$ ions is significantly slower in the presence of an $\mathrm{Ag}$ deposit, attributed with a standard rate constant lower than $10^{-4} \mathrm{~cm} \mathrm{~s}^{-1}$.

When the concentration of $\mathrm{DMFC}_{(\mathrm{NB})}$ is close to the concentration of $\mathrm{Ag}^{+}(\mathrm{W})$, the $\mathrm{W}-\mathrm{NB}$ interface can be blocked with a highly dense silver film, which is evidenced by the AFM image in Figure 2B. These results are in agreement with a previous study ${ }^{8}$ where very smooth silver films at the $\mathrm{W}-\mathrm{NB}$ and $\mathrm{W}-n$-octanol interface were formed. In some cases, the density of the Ag film is so high that it prevents completely the ion transfer across the interface. This is the reason for complete vanishing of the voltammetric response of the thinfilm electrode (curve 1 in Figure 4A). Interestingly, following an addition of $\mathrm{K}_{3}\left[\mathrm{Fe}(\mathrm{CN})_{6}\right]$ to the aqueous phase, the response of the electrode was restored (curve 2 in Figure 4A). As shown by cyclic voltammograms in Figure $4 \mathrm{~B}$, the overall process has properties of a reductive catalytic electrode mechanism.

Following open circuit Ag-deposition described by reaction $\mathrm{IV}$, the $\mathrm{NB}$ film contains $\mathrm{DMFC}^{+}{ }_{(\mathrm{NB})}$ and $\mathrm{NO}_{3}{ }^{-}{ }_{(\mathrm{NB})}$ ions, and unreacted $\mathrm{DMFC}_{(\mathrm{NB})}$. When the $\mathrm{W}-\mathrm{NB}$ interface is blocked by a dense Ag-film, the electrode oxidation of DMFC (reaction II) cannot proceed due to the prevention of the charge compensating ion transfer reaction III. However, in a cathodic potential scan (Figure 4B), the reduction of $\mathrm{DMFC}^{+}(\mathrm{NB})$ to $\mathrm{DMFC}_{(\mathrm{NB})}$ can proceed, if only is coupled by a simultaneous charge compensating the heterogeneous redox reaction between $\mathrm{DMFC}_{(\mathrm{NB})}$ and $\left[\mathrm{Fe}(\mathrm{CN})_{6}\right]^{3-}{ }_{(\mathrm{W})}$ to form $\mathrm{DMFC}^{+}{ }_{(\mathrm{NB})}$ and $\left[\mathrm{Fe}(\mathrm{CN})_{6}\right]^{4-}(\mathrm{W})$. The overall mechanism is represented by the following reactions:

$$
\begin{gathered}
\mathrm{DMFC}_{(\mathrm{NB})}^{+}+\mathrm{e} \rightarrow \mathrm{DMFC}_{(\mathrm{NB})}(\mathrm{GE}-\mathrm{NB}) \\
\mathrm{DMFC}_{(\mathrm{NB})}+\left[\mathrm{Fe}(\mathrm{CN})_{6}\right]_{(\mathrm{W})}^{3-} \rightarrow \\
\mathrm{DMFC}_{(\mathrm{NB})}^{+}+\left[\mathrm{Fe}(\mathrm{CN})_{6}\right]_{(\mathrm{W})}^{4-}(\mathrm{NB}-\mathrm{W})
\end{gathered}
$$

This electrode mechanism excludes the ion transfer across the
W-NB interface and couples two electron-transfer reactions that are happening at separate interfaces. For these reasons, the shape of voltammograms is typical for reductive catalytic systems in which the initial reactant, i.e., $\mathrm{DMFC}_{(\mathrm{NB})}^{+}$, is chemically regenerated in the course of the voltammetric experiment by means of heterogeneous redox reaction VI. However, it should be emphasized that, although reaction VI is a spontaneous process, it cannot proceed without electrode reaction $\mathrm{V}$. In the absence of the latter reaction, the redox reaction VI would require a charge-compensating anion transfer, which is prevented by the dense Ag film.

Experiments conducted in the presence of $\left[\mathrm{Fe}(\mathrm{CN})_{6}\right]^{4-}(\mathrm{W})$ demonstrated that the silver deposit at the $\mathrm{W}-\mathrm{NB}$ interface acted as an effective conductive medium for an electron exchange reaction between $\mathrm{DMFC}_{(\mathrm{NB})}$ and $\left[\mathrm{Fe}(\mathrm{CN})_{6}\right]^{4-}{ }_{(\mathrm{W})}$. In the absence of $\mathrm{Ag}$-particles, reaction VI proceeds according to a more complicated mechanism that causes a loss of the redox probe from the thin film and a decrease of the response of the electrode.

In the controlled potential deposition protocol, it is again reaction IV that occurs at the $\mathrm{W}-\mathrm{NB}$ interface. Note that during the open circuit deposition, the amount of the deposit is limited by the exhaustion of DMFC from the NB film. Contrary to this phenomenon, during the controlled potential deposition protocol, $\mathrm{DMFC}^{+}(\mathrm{NB})$ is electrochemically converted back to $\mathrm{DMFC}_{(\mathrm{NB})}$ by repetitive cycling of the electrode potential. This enables continuation of reaction IV in the course of the voltammetric experiment, without being limited by exhaustion of DMFC in the thin NB film. Hence, in the controlled potential deposition, the redox couple $\mathrm{DMFC} / \mathrm{DMFC}{ }^{+}$serves as a mediator to shuttle electrons from the electrode to the $\mathrm{W}-\mathrm{NB}$ interface, which are consumed by $\mathrm{Ag}^{+}$(W) ions. Therefore, the overall mechanism represents an electrochemical deposition of silver at the $\mathrm{W}-\mathrm{NB}$ interface. The initial clusters of Ag particles deposited at the $\mathrm{W}-\mathrm{NB}$ interface serve as additional support for further $\mathrm{Ag}$ deposition. The overall effect is manifested as an increase of the surface area for interfacial metal deposition. For these reasons, the response of the electrode increases in proportion with time in the course of the controlled potential deposition protocol (Figures 5 and 6), and the overall dependence of the SW net peak current versus deposition time has a shape of an isotherm (inset of Figure 5A). At a constant concentration of the organic redox probe, the slope of the rising portion of the isotherm, together with the critical time required to reach saturation, is dependent only on the $\mathrm{Ag}^{+}$(W) concentration (inset of Figure 5A). All these results prove that the voltammetric response recorded in the course of the controlled potential deposition procedure represents the Ag deposition at the $\mathrm{W}-\mathrm{NB}$ interface.

In addition to concentrations of $\mathrm{DMFC}_{(\mathrm{NB})}$ and $\mathrm{Ag}^{+}(\mathrm{W})$, the rate of reaction IV depends on the potential difference at the W-NB interface. Results in Figure 7 evidently illustrate this effect. The overall rate of the deposition process is higher for $\Delta_{\mathrm{W}}^{\mathrm{NB}} \phi=-74 \mathrm{mV}$ (curve 2 in Figure 7) compared to the potential difference of $\Delta_{\mathrm{W}}^{\mathrm{NB}} \phi=80 \mathrm{mV}$ (curve 1 in Figure 7). Moreover, the maximum of curve 2 is located at shorter critical time than that of curve 1 , indicating that the commencement of the saturation process occurs earlier for $\Delta_{\mathrm{NB}}^{\mathrm{W}} \phi=-74 \mathrm{mV}$ than for $\Delta_{\mathrm{NB}}^{\mathrm{W}} \phi=80 \mathrm{mV}$. These results show that the potential difference of $-74 \mathrm{mV}$ at the $\mathrm{W}-\mathrm{NB}$ interface, which is defined as $\Delta_{\mathrm{NB}}^{\mathrm{W}} \phi=\phi_{\mathrm{NB}}-\phi_{\mathrm{W}}$, accelerates the electron transfer from DMFC embedded in $\mathrm{NB}$ to $\mathrm{Ag}^{+}$in the aqueous phase. These results provide another support to the conclusion that the increase of the current in the controlled potential deposition 
protocol is a consequence of the Ag-deposition at the $\mathrm{W}-\mathrm{NB}$ interface through interfacial reaction IV.

Finally, results presented in Figure 8 reveal the strong catalytic effect of the $\mathrm{Ag}$ particles toward heterogeneous redox reaction between $\mathrm{DMFC}_{(\mathrm{NB})}$ and $\mathrm{H}_{2} \mathrm{O}_{2}(\mathrm{~W})$. Curve 2 in Figure $8 \mathrm{~A}$ shows that $\mathrm{DMFC}^{+}{ }_{(\mathrm{NB})}$ and $\mathrm{H}_{2} \mathrm{O}_{2}(\mathrm{~W})$ exchange electrons across the $\mathrm{NB}-\mathrm{W}$ interface according to the following reaction scheme:

$$
\begin{gathered}
\mathrm{DMFC}_{(\mathrm{NB})}^{+}+\mathrm{X}_{(\mathrm{NB})}^{-}+\mathrm{e} \rightarrow \\
\mathrm{DMFC}_{(\mathrm{NB})}+\mathrm{X}_{(\mathrm{W})}^{-}(\mathrm{GE}-\mathrm{NB})(\mathrm{VII}) \\
\mathrm{DMFC}_{(\mathrm{NB})}+\mathrm{H}_{2} \mathrm{O}_{2(\mathrm{~W})}+\mathrm{H}_{(\mathrm{W})}^{+}+\mathrm{X}_{(\mathrm{W})}^{-} \rightarrow \\
\mathrm{DMFC}_{(\mathrm{NB})}^{+}+2 \mathrm{H}_{2} \mathrm{O}_{(\mathrm{l})}+\mathrm{X}_{(\mathrm{NB})}^{-}(\mathrm{NB}-\mathrm{W})(\mathrm{VIII})
\end{gathered}
$$

Curve 3 in Figure 8A and curve 2 in Figure 8B obviously show that the rate of reaction VIII is strongly accelerated in the presence of $\mathrm{Ag}$ particles deposited at the $\mathrm{W}-\mathrm{NB}$ interface.

\section{Conclusion}

In this study thin organic film modified electrodes are applied to form and deposit Ag particles at the $\mathrm{W}-\mathrm{NB}$ interface. The experimental methodology proposed is straightforward but highly sensitive to the amount and properties of the metal deposit at the $\mathrm{L}-\mathrm{L}$ interface. In the open circuit deposition protocol, the dimensions of the Ag nanoparticles can be tuned by adjusting concentrations of DMFC in nitrobenzene and $\mathrm{Ag}^{+}$ions in the aqueous phase. The anticipated controlled potential deposition can be regarded as the electrochemical reduction of $\mathrm{Ag}^{+}$at the $\mathrm{W}-\mathrm{NB}$ interface, where the redox probe, serving as a mediator, shuttles electrons from the electrode to the $\mathrm{W}-\mathrm{NB}$ interface. In this deposition protocol, the amount of the deposited Ag particles can be electrochemically controlled. Most importantly, this simple electrode assembly enables studying of the catalytic activities of the metal particles deposited at the $\mathrm{L}-\mathrm{L}$ interface toward heterogeneous electron-transfer reactions in a simple and insightful procedure. The catalytic effect of Ag particles toward the heterogeneous electron exchange reaction between DMFC dissolved in nitrobenzene and $\mathrm{H}_{2} \mathrm{O}_{2}$ and $\left[\mathrm{Fe}(\mathrm{CN})_{6}\right]^{3-}$ dissolved in water is demonstrated for the first time.

Acknowledgment. The authors take the opportunity to acknowledge gratefully the financial support of the Alexander von Humboldt Foundation. Stimulating discussions with Prof. F. Scholz are gratefully acknowledged. Both authors wish to thank Mariana Chirea from the Faculty of Sciences in Porto for recording the AFM images. R.G. also thanks Fundação para a Ciência e a Tecnologia (FCT) of Portugal for providing of a post-doctoral fellowship (SFRH/BPD/14894/2004).

\section{References and Notes}

(1) Lahtinen, R.; Jensen, H.; Fermin, D. J. In Interfacial Catalysis; Volkov, A. G., Ed.; Marcel Dekker: New York, 2003; pp 611-633.
(2) Yogev, D.; Efrima, S. J. Phys. Chem. B 1988, 92, 5754.

(3) Kumar, A.; Mandal, S.; Mathew, S. P.; Selvakannan, P. R.; Mandale, A. B.; Chaudhari, R. V.; Sastry, M. Langmuir 2002, 18, 6478. (4) Dryfe, R. A. W.; Simm, A. O.; Kralj, B. J. Am. Chem. Soc. 2003, $125,13014$.

(5) Su, B.; Abid, J. P.; Fermin, D. J.; Girault, H. H.; Hoffmannova, H.; Krtil, P.; Samec, Z. J. Am. Chem. Soc. 2004, 126, 915.

(6) Zheng, L.; Li, J. J. Phys. Chem. B 2005, 109, 1108.

(7) Sakata, J. K.; Dwoskin, A. D.; Vigorita, J. L.; Spain, E. M. J. Phys. Chem. B 2005, 109, 138.

(8) Scholz, F.; Hasse U. Electrochem. Commun. 2005, 7, 541.

(9) Swami, A.; Kumar, A.; D’Costa, M.; Pasricha, R.; Sastry, M. J. Mater. Chem. 2004, 14, 2696.

(10) Gu, H.; Yang, Z.; Gao, J.; Chang, C. K.; Xu, B. J. Am. Chem. Soc. 2005, 127, 34-35.

(11) Knake, R.; Fahmi, A. W.; Tofail, S. A. T.; Cohessy, J.; Mihov, M.; Cunnane, V. J. Langmuir 2005, 21, 1001.

(12) Reetz, M. T.; Helbig, W. J. Am. Chem. Soc. 1994, 116, 7401.

(13) Guainazzi, M.; Silvestri, G.; Serravalle, G. Chem. Commun. 1975, 200.

(14) Cheng, Y. F.; Schiffrin, D. J. J. Chem. Soc., Faraday Trans. 1996, 92,3865 .

(15) Johans, C. R. C.; Kontturi, K.; Schiffrin, D. J. J. Electroanal. Chem. 2002, 526, 29.

(16) Johans, C.; Liljeroth, P.; Kontturi, K. Phys. Chem. Chem. Phys 2002, 4, 1067 .

(17) Johans, C.; Lahtinen, R.; Kontturi, K.; Schiffrin, D. J. J. Electroanal. Chem. 2000, 488, 99.

(18) Johans, C.; Clohessy, J.; Fantini, S.; Kontturi, K.; Cunnane, V. J. Electrochem. Commun. 2002, 4, 227.

(19) Lahtinen, R.; Johans, C.; Hakkarainen, S.; Coleman, D.; Kuntturi, K. Electrochem. Commun. 2002, 4, 479.

(20) Lahtinen, R. M.; Fermin, D. J.; Jensen, H.; Kontturi, K.; Girault, H. H. Electrochem. Commun. 2002, 2, 230.

(21) Scholz, F.; Komorsky-Lovrić, S.; Lovrić, M. Electrochem. Commun. 2000, 2, 112 .

(22) Shi, C.; Anson, F. C. Anal. Chem. 1998, 70, 3114.

(23) Shi, C.; Anson, F. C. J. Phys. Chem. B 1998, 102, 9850.

(24) Shi, C.; Anson, F. C. J. Phys. Chem. B 1999, 103, 6283.

(25) Komorsky-Lovrić, S.; Riedl, K.; Gulaboski, R.; Mirčeski, V.; Scholz, F. Langmuir 2002, 18, 8000.

(26) Bouchard, G.; Galland, A.; Carrupt, P.-A.; Gulaboski, R.; Mirčeski, V.; Scholz, F.; Girault, H. H. Phys. Chem. Chem. Phys. 2003, 5, 3748. 1262 .

(28) Gulaboski, R.; Mirčeski, V.; Scholz F. Electrochem. Commun. 2002 $4,277$.

(29) (a) Gulaboski, R.; Scholz, F. J. Phys. Chem. B 2003, 107, 5650. (b) Gulaboski, R.; Galland, A.; Bouchard, G.; Caban, K.; Kretschmer, A.; Carrupt, P.-A.; Stojek, Z.; Girault, H. H.; Scholz, F. J. Phys. Chem. B 2004, $108,4565$.

(30) Scholz, F.; Gulaboski, R.; Caban, K. Electrochem. Commun. 2003, $5,929$.

(31) Scholz, F.; Gulaboski, R. Faraday Discuss. 2005, 129, 169.

(32) Scholz, F.; Gulaboski, R. ChemPhysChem 2005, 6, 16.

(33) Scholz, F.; Schröder, U.; Gulaboski, R. Electrochemistry of Immobilized Particles and Droplets; Springer: Heidelberg, Berlin, 2005.

(34) Quentel, F.; Mirčeski, V.; L’Her, M. Anal. Chem. 2005, 77, 1940.

(35) Quentel, F.; Mirčeski, V.; L'Her, M.; Mladenov, M.; Scholz, F.; Elleouet, C. J. Phys. Chem. B 2005, 109, 13228.

(36) Mirčeski, V. J. Phys. Chem. B 2004, 108, 13719.

(37) Mirčeski, V.; Quentel, F.; L’Her; Pondaven, A. Electrochem. Commun. 2005, 7, 1122 . 23. 